$1-1-2015$

\title{
Predictors of Stress and Coping Strategies of US Accelerated vs. Generic Baccalaureate Nursing Students: An Embedded Mixed Methods Study
}

Linda Wolf

Cleveland State University, linda.wolf14@gmail.com

Andrea Warner Stidham

Hiram College

Ratchneewan Ross

Kent State University

Follow this and additional works at: https://engagedscholarship.csuohio.edu/nurs_facpub

Part of the Nursing Commons

How does access to this work benefit you? Let us know!

\section{Recommended Citation}

Wolf, Linda; Stidham, Andrea Warner; and Ross, Ratchneewan, "Predictors of Stress and Coping Strategies of US Accelerated vs. Generic Baccalaureate Nursing Students: An Embedded Mixed Methods Study" (2015). Nursing Faculty Publications. 41.

https://engagedscholarship.csuohio.edu/nurs_facpub/41

This Article is brought to you for free and open access by the School of Nursing at EngagedScholarship@CSU. It has been accepted for inclusion in Nursing Faculty Publications by an authorized administrator of EngagedScholarship@CSU. For more information, please contact library.es@csuohio.edu. 


\title{
Predictors of Stress and Coping Strategies of US Accelerated vs. Generic Baccalaureate Nursing Students: An Embedded Mixed Methods Study
}

\author{
Linda Wolf , Andrea Warner Stidham , Ratchneewan Ross
}

\section{Introduction}

Stress is an inevitable part of life and is especially pervasive in the lives of nursing students. Baccalaureate nursing students, both generic and accelerated, experience a great deal of stress due to the intensity of the academic and clinical components of their nursing programs. Generic students are those who are working to complete their studies in a traditional 4 year BSN program, whereas accelerated students are those who have previously completed a Baccalaureate or higher degree and are completing their nursing coursework within 14 months 2 years. Educators can decrease stress by teaching stress reduction tech niques, thus providing students with positive lifelong coping strategies.
Use of social support in the form of family and friends for stress manage ment has been extensively studied with nursing students while social support from faculty and peers remains understudied (Reeve et al., 2013) although social support from faculty was found to decrease stu dent stress (Muirhead and Locker, 2008). With the emphasis on student engagement and student success, there is a need for increased faculty awareness of student stress. Luo and Wang (2009) found that by improving students' coping skills, problem solving ability improved. This aim of this study was to identify the (1) predictors of stress; and (2) stressors and coping strategies used by accelerated and generic U.S. nursing students.

\section{Background/literature}

Studies of stress in nursing students began in the 1930s. Results of those studies are consistent with studies conducted today (Gibbons 
et al., 2009; Reeve et al., 2013). In 1939, nursing students identified (1) concerns regarding relationships with faculty, physicians, and patients, (2) fatigue, (3) graduating, and (4) "social, personal, and emo tional problems" (Torrop, 1939, p. 177). Recent studies have shown that for today's nursing students, practice in the clinical setting is a major source of stress. Not only must students deal with interpersonal interac tions with clinical instructors and nursing staff, but they also are stressed by their Jack of knowledge; insecurity with clinical skills; caring for dying patients; fear of failure (Gibbons et al., 2009; Gibbons, 2010 , Jimenez et al., 2010); and clinical placements (Pryjmachuk and Richards, 2007). While mild levels of stress can have a positive effect on students by offer ing alternative solutions to problems, and increasing motivation, high stress levels can lead to depression (Zebb and Beck, 1998; Ross et al., 2005).

No general consensus exists as to which year of the program is most stressful for nursing students. Some studies have reported that stress in creases as a student progresses through the nursing program (Lindop, 1991; Tully, 2004;Jimenez et al., 2010), but Lo (2002) found that second year students experience the highest levels of stress. Severity of stress has been found to differ among types of nursing programs (Lindop, 1991; Tully, 2004; Jimenez et al., 2010).

Studies also revealed that use of positive coping strategies lessens student stress (Gibbons et al., 2007; Hegge and Larson, 2008). For students social support in the form of familyand friends was the primary and most positive coping strategy used for stress reduction (Lindop, 1991; Lo, 2002; Ross et al., 2005; Gibbons et al., 2007). Although faculty were sought for support in matters pertaining clinical experiences and performance (Mahat, 1998), many students preferred to work out their difficulties alone (Gibbons et al., 2009). Hsiao et al. (2010) in a study of students in Taiwan found that nursing students possessing strong spiri tuality experienced Jess clinical stress.

Students engage in negative as well as positive coping skills. Studies have found that a small number turn to drugs and alcohol (Timmins et al., 2011, p. 764) indicating a need for promotion of alcohol and drug reduction.

Cognitive appraisal of events or circumstances as stressful or threat ening by the individual is the underlying framework for this research (Folkman et al., 1986). The unique individual interpretation of situa tions means that any shared situation or condition may be perceived differently within the group, so that an individual may be more or Jess affected than others in the group. Allowing for this variation, there are events or circumstances that may be commonly seen as stressful. Identification of those common worries would be signifi cant in understanding the accumulation of stress or allostatic load of the student.

Specific predictors comparing stress of US generic and accelerated BSN students has not been found, nor has a comparison of coping strat egies used by US accelerated and generic BSN students. Accelerated BSN students may have higher levels of stress than generic students due in part to the rapid pace and intensity of the program. No mixed methods research has been found to gain an understanding about students' stress, especially juxtaposing generic versus accelerated nursing students based on quantitative and qualitative results. Results from this study can be used to help students use coping strategies tailored to their circumstances, thereby facilitating learning and increasing student success. The objectives of this study were (1) to identify the pre dictors of stress between generic and accelerated BSN students; (2) to describe stressors and coping strategies used by accelerated BSN students in comparison with generic students.

\section{Methods}

\section{Design}

This embedded mixed methods study is part of a larger study which examined predictors ofdepression among BSN students in four countries
(Japan, Taiwan, Thailand, and the USA). It primarily focused on the cross sectional, correlational quantitative arm (postpositivist philosophy) to examine predictors of stress, with qualitative data (constructivist philos ophy) embedded to provide supportive information on stress and coping strategies among accelerated and generic nursing students at two Mid west universities (Creswell and Plano Clark, 2011) (Fig. 1). A question naire packet consisting of demographics, history of depression, the Perceived Stress Questionnaire, Rosenberg Self Esteem Scale, Multidi mensional Scale of Perceived Social Support (to collect quantitative data), and open ended questions (to collect qualitative data) was admin istered to participants.

\section{Participants}

Institutional Review Board (IRB) approvals were obtained from six universities in the four countries. Participants were a convenience sam pie of 210 junior and senior generic and accelerated undergraduate nursing students in two nursing programs in the Midwest There were 135 generic junior and senior students and 75 accelerated junior and senior students. Students were approached after class and were invited to participate in the study. The purpose, risks, and benefits of the study were explained; students were informed that confidentiality and ano nymity would be maintained; and that participation was voluntary and that they could withdraw at any point. Students agreeing to partic ipate were given consent forms and questionnaires. Demographic data collected consisted of age, gender, year in the nursing program, and previous degree(s). Students who completed the questionnaire re ceived a $\$ 5.00$ gift certificate to a restaurant.

\section{Instruments}

Three reliable, validated, widely used instruments were utilized in paper and pencil format to identify predictors of stress: The Perceived Stress Questionnaire (PSQ; Levenstein et al., 1993), Rosenberg Self Esteem Scale (R SE; Rosenberg, 1989), and Multidimensional Scale of Perceived Social Support (MSPSS; Zimet et al., 1988). Five open ended questions asked participants about their concerns in their per sonal life as well as the nursing program; how they were handling these concerns; and to include thoughts on any other issues of concern.

\section{Data Analysis}

Quantitative data were analyzed using descriptive statistics to de scribe the sample and simultaneous multiple regression to examine

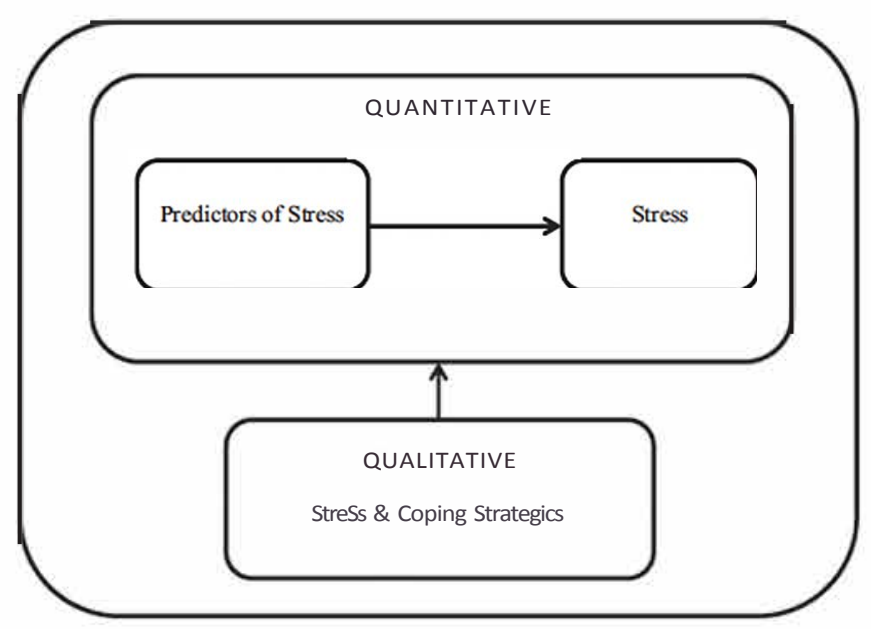

Fig. 1. Embedded Correlational Model of Predictors of Stress and Coping Strategies in Accelerated vs. Generic 8SN Students. 
predictors of stress, using the SPSS version 21. Conventional content analysis was used to analyze the qualitative data (Hsieh and Shannon, 2005). Categories emerged from carefully, but openly reading student narratives. Using open coding, data were analyzed by breaking them into discrete events, incidents, or ideas thoroughly examining each while comparing and contrasting for similarities and differences (Strauss and Corbin, 1998). Conceptual similarities and differences were grouped into categories. Labels were given to these categories to represent the context of the data. Once this was completed data were an alyzed using axial coding to look for relationships between the catego ries and identify links to subcategories (Strauss and Corbin, 1998). Once axial coding was completed selective coding was done to refine and integrate the categories identified during axial coding. Participant responses were reviewed by three researchers in an open, conventional content analysis in order to describe a phenomenon (Hsieh and Shannon, 2005).

\section{Quantitative Results}

\section{Demographics}

Seventy five accelerated students and 135 generic students partici pated in this study. Sixty percent were seniors and the rest were juniors. More accelerated students were older and had family (46\%) than generic students (34\%). Most students in both groups had adequate income (89\%).

\section{Predictors of Stress}

Means and standard deviations of the scores for stress, emotional support, and self esteem are shown in Table 1. When an independent $t$ test was performed, no stress score difference was found between the accelerated and generic groups $(\mathrm{t}=.46, p=.65)$. Results of simul taneous multiple regression confirmed that the type of program (accel erated vs. generic) was not associated with stress levels. However, history of depression, year in the program, self esteem, and social support were significant predictors of stress. History of depression and year in the program were positively related to stress $(\beta=.166$ and $\beta$ $=.159$, respectively) with 4 th year students having higher levels of stress than 3rd year students. Participants with higher self esteem had lower levels of stress than those with low self esteem $(\beta=.270)$. Participants who had emotional support from family and friends experienced lower stress than students with less emotional support $(\beta=.179)$. The whole model yielded $16 \%$ of the explained variance accounted for by the four predictors (Table 2 ).

\section{Qualitative Findings}

Three categories of stressors were identified: (1) fear of failures and incompetence in clinical; (2) problematic relationships; and (3) time management issues.

\section{Fear of Failure and Incompetence in Clinical}

School related stressors shared two common threads in our study. The same percentage of students (22\% each for generic and accelerated

Table 1

Scores of Stress, Emotional support, and Self-esteem $(\mathrm{N}=210)$.

\begin{tabular}{llll}
\hline & $\begin{array}{l}\text { Accelerated } \\
\text { Mean (SD) } \\
(\mathrm{n}=75)\end{array}$ & $\begin{array}{l}\text { Generic } \\
\text { Mean (SD) } \\
(\mathrm{n}=135)\end{array}$ & Possible Scores \\
\hline Stress & $41.4(6.84)$ & $42.0(6.70)$ & $0-60$ \\
Emotional support & $69.1(12.77)$ & $69.0(11.62)$ & $7-84$ \\
Self-esteem & $15.9(1.78)$ & $16.1(2.36)$ & $0-30$ \\
\hline
\end{tabular}

Table 2

Summary of Simultaneous Regression Analysis for Variables Predicting Stress ( $N=210)$.

\begin{tabular}{|c|c|c|c|c|c|}
\hline Variable & B & SE & $\beta$ & $t$ & p-value \\
\hline Accel. vs Generic & .076 & 1.400 & .003 & .054 & .957 \\
\hline $\begin{array}{l}\text { History of depression } \\
\text { (yes vs. no) }\end{array}$ & 4.299 & 1.722 & .166 & 2.496 & $.013^{*}$ \\
\hline $\begin{array}{l}\text { Year in program } \\
\text { (Junior vs. Senior) }\end{array}$ & 3.424 & 1.383 & .159 & 2.476 & $.014^{*}$ \\
\hline $\begin{array}{l}\text { Gender } \\
\quad \text { (male vs. female) }\end{array}$ & -1.674 & 1.956 & -.055 & -.856 & .393 \\
\hline $\begin{array}{l}\text { Make ends meet } \\
\text { (yes vs. no) }\end{array}$ & -4.119 & 2.126 & -.125 & -1.937 & .054 \\
\hline Emotional Support & -.156 & .057 & -.179 & -2.752 & $.006^{* *}$ \\
\hline Self-esteem & -1.301 & .309 & -.270 & -4.215 & $.0001^{* * *}$ \\
\hline
\end{tabular}

Adjusted $\mathrm{R}^{2}=.160\left(\mathrm{~F}=6.70, p\right.$-value $\left.=.0001^{* * *}\right)$

${ }^{* * *} \mathrm{p}<.001,{ }^{* *} \mathrm{p}<.01,{ }^{*} \mathrm{p}<.05$

students) was identified regarding fears of failures in classroom and clinical settings. Both accelerated and generic students identified fears of failure to graduate ( $64 \%$ vs. $52 \%$ ); failing coursework (28.5\% vs. $21 \%$ ); failing clinical (32\% vs. $6.5 \%$ ); and failing the NCLEX ( $42.8 \%$ vs. $34 \%)$. An accelerated student stated "Being a student nurse can be diffi cult, sometimes I feel nervous about clinical and if I will make a mis take." A generic student stated, "I worry most about making a mistake in clinical setting that might harm someone." Although accelerated students voiced similar concerns as generic students, their concerns were regarding acquisition and application of knowledge in the clinical setting due to the pace of the program. One student stated, "I worry that I won't get through the program and if I do, will I know enough when I start my practice." Another stated, "Will I be able to bring everything together that I learned in school when I start my career?"

\section{Problematic Relationships}

Problematic relationships between students and faculty were identi fied as stressful by both accelerated and generic students (about $13 \%$ in each group). Students described situations in which they felt that facul ty and clinical instructors lacked awareness of timing of examinations and assignments and negative behaviors of clinical instructors. An accel erated student stated, "Never have I met a group of impersonal, uncar ing, cold hearted instructors like the ones I have now." Another accelerated student stated, "The amount of disrespect that I have expe rienced from this school is huge." Generic students voiced similar thoughts such as "[a] big problem with some professors respecting students and vice versa... while another generic student stated "I feel many of the faculty engage in hazing like behaviors towards the students."

\section{Time Management Issues}

Students experience time management problems from academics and clinical. The high intensity of the program created stress in both the academic and clinical settings. Concerns of lack of time were noted by both generic and accelerated students, regarding timing of examinations and papers as well as the demand of clinical. Seventeen percent of the accelerated students and $13 \%$ of the generic students reported time management to be stressful. "Lack of time to do things that need to be done/fear of failure," as well as, "I find it hard to keep track of multiple deadlines, for the many assignments that are given to us." One generic student stated: "It has been really stressful because I feel like I don't have enough time to learn everything I need to." One student described the stress of the accelerated program: "The accelerat ed program can feel really stressful especially with the large amount of paper work we have to do for our assignments and the long days that we have. ... sometimes feel rushed in trying to learn certain nursing skills." 


\section{Coping Strategies}

\section{Positive Thinking}

This study revealed that 55 (39\%) generic students and 40 (63\%) of accelerated students engaged in positive thinking as a coping strategy. Accelerated students stated, "I have never failed a class and I won't let myself now," and "Keep studying, stay focused, search our resources (faculty, professors), and ask questions." Other statements included, "try to adapt and not worry", "try my best", and "I know I can do it... and do it well." Generic students stated "Learn what I can and realize that I will learn as I go," and "Study hard and accept my grades for what they are and what I can do. One generic student stated, "I practice often and try very, very hard. I try to maintain a positive outlook as I realize I am a beginner and am often too self critical."

\section{Social Support}

Social support was integrated into several students' lives to ease the stress of the nursing program. Nursing students (4\% for generic and $8 \%$ for accelerated) primarily sought social support from family and friends. An accelerated student commented, "I talk with instructors and current RNs who have experience." Similarly, a generic student stated, "I talk with friends that are nurses and other friends and family about the rigors and stresses of the nursing program."

\section{Discussion}

Although previous research found that both generic and accelerated students experienced high levels of stress (Ross et al., 2005; Hegge and Larson, 2008), no studies simultaneously examined the differences of stress in both groups of students. Our study was the first to compare stress levels of nursing students in the accelerated and generic pro grams and found that stress levels did not differ between accelerated and generic students. Students who are older and have family tend to be less stressed than those who are younger and single because they are more likely to be more mature psychologically and have more problem solving skills (Beck and Srivastava, 1991). Although the accel erated students in our study were likely to be older and had family, the intensity and the fast pace of the accelerated program could have inten sified their stress (Hegge and Larson, 2008). Thus, their stress levels were not different from those of generic students. Hence, it is equally important to screen for stress levels in both groups of students.

The predictors of stress identified in our study included self esteem, emotional support, history of depression, and year in the program. Quantitatively, both accelerated and generic students with high self esteem and high emotional support reported less stress. The qualitative results provided supportive information in that when a student has confidence and uses positive thinking (concepts highly related to self esteem), she is likely to use active coping strategies such as working hard. Such active coping strategies are found to be utilized successfully in nursing students in Taiwan and Thailand, which in turn, increases students' academic success and lessens their stress and mental distress (Sheu et al., 2002; Ross et al., 2014). Positive thinking emerged as an unexpected coping strategy in our study and is only identified as a cop ing strategy in one previous study in Singapore (Wong, 2012). While previous research found students engaging in negative coping strategies (Luo and Wang, 2009), none were identified in our study.

Quantitatively, emotional support was a significant predictor of stress in the present study. Our qualitative results confirmed that sever al students brought up social support as a source of positive coping strategy to combat stress. The source of social support commonly used in our participants included family and friends. Social support within a peer network was not evident. Our results are in line with previous studies in other countries which indicated that support from family and friends were negatively associated with stress and depression (Gibbons et al., 2007; Lo, 2002; Ross et al., 2005).

While the quantitative results revealed predictors of stress, our qual itative results helped identify stressors which included fears of failures and incompetence in clinical, problematic relationships, and time man agement issues. Fear of academic failure and incompetence in the clini cal setting were significant sources of stress for both groups of students. This was evenly split between the generic and accelerated students at $22 \%$. Our findings are consistent with previous research in different countries. For example, Ross et al. (2014) found that school and time management, negative relationships with faculty, and fear of failing both in class and clinical were described among Thai BSN students. Jimenez et al. (2010) found that Spanish nursing students perceived work in the clinical and classroom settings as stressful, but more so in the clinical setting.

In our study, students with a history of depression reported higher levels of stress than those without a history of depression. Senior students experienced more stress than junior students. This result is in line with previous studies among nursing students which showed that stress increases as a student progresses through the nursing program (Tully, 2004; Lindop, 1991; Jimenez et al., 2010), Thus, stress screening and stress reduction should be established, especially when senior nursing students are identified to have a history of depression.

\section{Conclusions and Recommendations}

This study demonstrates that specific predictors of stress of nursing students can be identified in U.S. accelerated and generic BSN students. Self esteem was the strongest predictor of stress, followed by emotional support, a history of depression, and year in the program. Students with higher levels of self esteem had lower levels of stress as did students with higher levels of emotional support. Stressors identified by the accelerated and generic BSN students were fears of failures and clinical incompetence, problematic relationships (specifically with faculty), and time management issues.

Coping strategies identified were positive thinking and social support. Emotional support in the form of social support has been reported as a helpful coping strategy in stressful situations. Screening for and identifica tion of stress is essential. An annual stress screening should be performed. A stress reduction program should include interventions that help increase students' self esteem, social support, and positive thinking. Because self esteem, a sense of self worth, is a learned phenomenon (Rosenberg, 1989), establishing study groups with support from faculty and peers will be helpful. Affirmations (positive self talk) can enhance positive thinking. An example of such a technique could be found via this URL: http://www.ahna.org/Resources/Stress Management/Managing Stress/Stress Exercises/Affirmations (American Holistic Nurses Association, n.d.).

Clearly, results of this study suggest institutions could make changes to positively impact, or reduce, stress in BSN students. Awareness of stress predictors allows for identification of at risk students. However, faculty must be educated in regard to indicators of stress to enable them to identify students so measures and/or referral to appropriate resources can be made. Providing stress reduction interventions to all students and referral to resources outside of the nursing program will allow all nursing students to work to their full potential. These coping strategies can arm faculty with the tools to assist students during the course of the program.

The strengths of this study include nursing students from two uni versities, one of which is an urban university providing a different per spective from that of the rural university. The use of mixed methods yielded both quantitative and qualitative results, enriching our under standing on stress and coping strategies among accelerated and generic students.

Limitations of the study are related to areas of data collection methods. Data collection was done at one point in time rather than 
longitudinally. Collecting data at midterm or near final examinations would potentially reveal higher stress levels which would not provide accurate report of stress. Use of semi structured interviews would disclose more in depth, thick, rich data. While these findings offer im portant information regarding experiences of U.S. BSN students, results may not be generalizable to students outside of the U.S. Finally, only positive coping strategies were described by our participants. This could be explained in that we did not specifically ask the students to describe their negative coping strategies in our study.

Future research should be undertaken at multiple universities other than the Midwest universities and with various nursing programs. Also, investigating the effects of positive thinking, through positive self talk will be helpful.

\section{Acknowledgements}

The author was a participant in the NLN Scholarly Writing Retreat, sponsored by the NLN Foundation and Pocket Nurse.

The larger study was funded by Kent State University Research Council, USA; The Ministry of Education, Japan; Saint Louis College, Thailand; Saku University, Japan; and Sigma Theta Tau Delta Xi Chapter, USA.

\section{References}

American Holistic Nurses Association, d. Affirmations. Retrieved from http://www.ahna. org/Resources/Stress-Management/Managing-Stress/Stress-Exercises/Affirmations.

Beck, D.L.,Srivastava, R., 1991. Perceived level and sources of stress inbaccalaureate nursing students. J. Nurs. Educ. 3, 127-133.

Creswell, J., Plano Clark, V., 2011. Designing and conducting mixed methods research. Sage Publication, Thousand Oaks, CA.

Folkman, S., Lazarus, R., Gruen, R., DeLongis, A., 1986. Appraisal, coping, health status, and psychological symptoms. J. Pers. Soc. Psychol. 50 (3), 571-579. http://dx.doi.org/10. 1037/0022-3514.50.3.571.

Gibbons, C., 2010. Stress, coping and burn-out in nursing students. Int. J. Nurs. Stud. 47, 1200-1309. http://dx.doi.org/10.1016/j.ijnurstu2010.02.015.

Gibbons, C., Dempster, M., Moutray, M., 2007. Stress and eustress in nursing students. J. Adv. Nurs. 61 (3), 282-290. http://dx.doi.org/10.1111/j.1365-2648.2007.x.

Gibbons, C., Dempster, M., Moutry, M., 2009. Surveying nursing students on their sources of stress: A validation study. Nurse Educ. Today 29, 867-872. http://dx.doi.org/10. 1016/j.nedt.2009.04.008.

Hegge, M., Larson Sr., V., 2008. Stressors and coping strategies of students in accelerated baccalaureate nursing programs. Nurse Educ. 33 (1), 26-30.

Hsiao, Y., Chien, L., Wu, L., Chiang, C., Huang, S., 2010. Spiritual health, clinical practice stress, depressive tendency and health-promoting behaviours among nursing students. J. Adv. Nurs. 66 (7), 1612-1622. http://dx.doi.org/10.1111/j.1365-2648. 2010.05328.x

Hsieh, H.F., Shannon, S.E., 2005. Three approaches to qualitative content analysis. Qual. Health Res. 15 (9), 1277-1288.
Levenstein, S.,Prantera, C.,Varvo, V.,Scribano, M.L.,Berto, E.,Luzi, C.,Andreoli, A., 1993. Development of the perceived stress questionnaire: a new tool for psychosomatic research. J. Psychosom. Res. 37, 19-32.

Jimenez, C., Martinez Navia-Osoria, P.,Vacas Diaz, C., 2010. Stress and health in novice and experienced nursing students. J. Adv. Nurs. 66 (2), 442-455.

Lindop, E., 1991. Individual stress among nurses in training: why some leave while others stay. Nurse Educ. Today 11, 110-120. http://dx.doi.org/10.1046/j.1365-2648.1999. 00974.x.

Lo, R., 2002. A longitutindal study of perceived level of stress, coping, and self-esteem of undergraduate nursing students: An Australian case study. J. Adv. Nurs. 39 (2), 967-973. http://dx.doi.org/10.1046/j.1365-2648.2000.02251.x.

Luo, Y.,Wang, H., 2008. Correlation research on psychological health impact on nursing students against stress, coping way and social support. Nurse Educ. Today 29, 5-8. http://dx.doi.org/10.1016/j.nedt.2008.05.019.

Mahat, G., 1998. Stress and coping: Junior baccalaureate nursing students in clinical settings. Nurs. Forum 22 (1), 11-19.

Muirhead, V., Locker, D., 2008. Canadian dental students' perceptions of stress and social support. Eur. J. Dent. Educ. 12 (3), 144-148.

Pryjmachuk, S., Richards, D., 2007. Mental health nursing students differ from other nursing students: Some observations from a study on stress and coping. Int. J. Ment. Health Nurs. 16, 390-402. http://dx.doi.org/10.1111/j.1447-0349.2007.00404.x.

Reeve, K.L., Shumaker, C.J., Yearwood, E.L., Crowell, N.A., Riley, J.B., 2013. Perceived stress and social support in undergraduate nursing students' educational experiences. Nurse Educ. Today 33 (4), 419-424. http://dx.doi.org/10.1016/j.nedt.2012.11.009.

Rosenberg, M., 1989. Society and the adolescent self-image (rev. ed.). Wesleyan University Press, Middletown, CT, England.

Ross, R., Zeller, R., Srisaeng, P., Yimmee, S., Sonchid, S., Sawatphanit, W., 2005. Depression, stress, emotional support, and self-esteem among baccalaureate nursing students in Thailand. Int. J. Nurs. Educ. Scholarsh. (ISSN: 1548-923X) 2 (1), 1-15.

Ross, R., Boonyanurak, P., Stopper, C., 2014. Worries and depressive symptoms among baccalaureate nursing students in Thailand: An embedded mixed methods study. J. R. Thai Army Nurses 15 (1), 52-65 (aaa.tcithaijo.org/index.php/JRTAN/article/download/18432/16208).

Sheu, S., Lin, H.-S., Hwang, S.-L., 2002. Perceived stress and physio-psycho-social status of nursingstudents during their initial period of clinical practice: The effect of coping behaviors. Int. J. Nurs. Stud. 39 (2), 165-175.

Strauss, A., Corbin, J., 1998. Basics of qualitative research: techniques and procedures for developing grounded theory (2nd ed.). Thousands Oaks, CA, Sage Publication.

Timmins, F., Corroon, A.M., Bryne, G., Mooney, B., 2011. The challenge of contemporary nurse education programmes. Perceived stressors of nursing students: mental health and related lifestyle issues. J. Psychiatr. Ment. Health Nurs. 18, 758-766. http://dx.doi. org/10.1111/j.1365-2850.2011.01780.x.

Torrop, H., 1939. Guidance programs in schools of nursing. Am. J. Nurs. 39, 176-186.

Tully, 2004. Stress, sources of stress and ways of coping among psychiatric nursing students. J. Psychiatr. Ment. Health Nurs. 11, 42-47.

Wong, S.S., 2012. Negative thinking versus positive thinking in a Singaporean student sample: Relationships with psychological well-being and psychological maladjustment. Learn. Individ. Differ. 22 (1), 76-82. http://dx.doi.org/10.1016/j.lindif.2011.11.013.

Zebb, B.J.,Beck, J.B., 1998. Worry versus anxiety: Is there really a difference? Behav. Modif. 22 (1), 45-61.

Zimet, G.D., Dahlem, N.W.,Zimet, S.G., Farley, G.K., 1988. The multidimensional scale of perceived social support. J. Pers. Assess. 52, 30-41. 